\title{
Asymmetric Relationship of Global Human Obesity and Political Globalization Through World Human Development Levels
}

Mubbasher Munir ( $\sim$ si3702@putra.unisza.edu.my )

University of Management and Technology https://orcid.org/0000-0001-7532-2512

Zahrah Tul Amani Zakaria

Universiti Sultan Zainal Abidin

Reda Alhajj

University of Calgary

Sultan Salem

University of Birmingham

Noman Arshed

University of Management and Technology

Research

Keywords: Obesity, Globesity, Political Globalization, Human Development Levels, Panel Data Analysis

Posted Date: December 21st, 2021

DOI: https://doi.org/10.21203/rs.3.rs-1116190/v1

License: (c) (1) This work is licensed under a Creative Commons Attribution 4.0 International License.

Read Full License 


\section{Abstract}

Background: Political globalization is a crucial and distinct component of strengthening global organizations. Obesity is a global epidemic in a few nations, and it is on the verge of becoming a pandemic that would bring plenty of diseases. The focus of this research is to see how the political globalization index affects worldwide human obesity in relation to global human development levels.

Methods: In order to assess any cross-sectional dependence among observed 109 nations, the yearly period from 1990 to 2017 is analyzed using second generation panel data methods. KAO panel cointegration test and Feasible Generalized Least Square model were used to meet our objectives.

Results: Low level of political Globalization tends to increase global human obesity because countries cannot sway international decisions and resources towards them. While the high level of political Globalization tends to reduce obesity because they can control and amends the international decisions. For the regression model, a feasible Generalized Least Square model was utilized. The study observed that the $\mathrm{R}$ squared values for all models are healthy, with a minimum of 87 percent variables explaining differences in global obesity at the country level.

Conclusion: There is a very important to tackle globalization issue to reduce global human obesity. Simplicity of dietary options and the amount of physical labour they undergo in their agricultural duties, an increase in rural population percentage tends to lower the average national obesity value.

\section{Introduction}

\section{Background}

Significant developments that have arisen since the 1960s have influenced this research. Cultures from all over the world bloomed and formed themselves in their own right at that time. On the other hand, rapid economic Globalization has radically altered market paradigms and government agendas, with farreaching implications for economies and communities, habitats and well-being, justice, and equality. The evidence for the argument that a Western diet alone causes poor health effects is mixed, contrary to many claims regarding the Westernization of diets around the world $(1,2)$.

Global trade liberalization, economic growth, and accelerated urbanization have contributed to a rise in obesity and associated chronic diseases worldwide. These trends continue to drive significant improvements in living conditions, foods, and behaviours that foster positive energy balance. Increases in animal fat and protein intake, processed grains, and added sugar are typical of nutritional transitions in low- and middle-income countries. As a result of more mechanized and technology-oriented lifestyles, there has been a decrease in physical activity.

Given the high costs of obesity and comorbidities in healthcare spending and quality of life, preventive efforts are critical, particularly in low- and middle-income countries, which must often deal with coexisting 
infectious diseases and malnutrition. Undernutrition and obesity will coexist in the same nation, culture, or household as countries grow more urbanized, posing a specific problem for health systems with limited funding. Because of the nature and scale of the obesity crisis, preventive initiatives and programs must be implemented at various levels to have a meaningful impact. High-level public initiatives from the international community and concerted campaigns from nations, organizations, societies, and people can all be part of the solution to positively affect behavioural change $(3,4)$. Obesity (BMI $30 \mathrm{~kg} / \mathrm{m} 2)$, formerly thought to be a concern only in the United States and other high-income Western nations, has become a significant contributor to the global burden of disease (4-6).

Determinants of obesity are of three types. The first determinant that covers diet and physical inactivity is known as the behavioural determinant. The second one covers physical activity and healthy food, known as the environmental determinant. Lastly, it covers cultural, political and economic factors that come under social determinants (7). To thoroughly look into this evolving epidemic, a description of nutrition transition and its implications globally were given (8) for obesity. This portrayed that populations gradually rise via a series of transitions consistent with changes in the growth of economy, culture, and urbanization. Insufficient and unstable food supplies gave obesity an evolution at Stage 3. High calorie processed foods followed by a reduction in physical activity at Stage 4 and lastly, the most dangerous stage consists of increased non-infectious diseases at Stage 5.

The behavioural change enables individuals to adopt positive eating habits and prefers not to delay physical activity to prevent these diseases. (9) study have explained obesity and malnourishment, burden as a whole was borne by many low and middle-income countries, which gave rise to the complexity of both problems and solutions. (10) suggested that obesity was becoming an inevitable epidemic that led people to be less active. Most obesity was seen in those countries that earned low and middle income, emerging this epidemic towards the destruction of the global economy. Evolving epidemics like obesity, diabetes and cardiovascular disease have been a side effect of Globalization in food supplies giving rise to health consequences. This paper discussed health initiatives outlined in WHO 2013 and emphasized moving towards social change rather than approaching individual behaviour change (11).

A Meta study conducted on Globalization affecting the democracy analyzed and used cross-sectional data of 127 countries and pooled in some factors that constructed the idea of Globalization, i.e., foreign direct investment inflows, portfolio investment flows, trade openness, and the flow of democratic ideas, which lead to the conclusion that foreign direct investment had a positive impact on democracy. In contrast, the idea of trade openness and portfolio investments showed a negative impact on the economy (12). One of the studies suggested that Globalization is one of the most influencing factors in states' welfare. Three welfare measures were analyzed, and a comprehensive study on the economic Globalization indicators. This study showed that Globalization has turned out in sceptical claims that welfare in the state is achieved with acquiring Globalization. The concept of Globalization does not significantly affect the economy, whereas political, social and economic factors show significance (13). 
Globalization was analyzed for enhancement in the economy, but the empirical evidence conflicts that the global economy exhibits the trends of increasing Globalization (14). Four types of mechanisms were used to identify the aspect of Globalization affecting land conversion. Cascade, rebound, displacement and remittances effects were the mechanisms used, resulting in the fact that there is a need for foreign capital investments and remittances to preserve forestry to produce food. This gave a concept that uncontrolled land expansion cannot apply with Globalization; instead, increased land efficiency could positively affect (15).

The supposed benefits of foreign lifestyles are more use of luxury vehicles, lower-calorie expenditures as well as foreign diets, and it may have expanded a population's understanding of the supposed benefits of social and cultural Globalization, including cross-border migration of cultures and media transparency, e.g., greater calorie consumption through nourishment-rich in fats and sugars. The impact of social Globalization on obesity may thus be compared to the impact of urbanization on further developments, which could be linked to a decrease in energy expenditure over time (16). Further increased supply and use of lower-cost, higher-calorie foods. $(8,10)$.

\section{Globalization And Obesity}

The term "globesity" has recently entered the English lexicon, implying a link between obesity and global market culture $(1,17)$. Several academics believe that Globalization is shifting diets, influencing lifestyles, altering demographic and economic circumstances, and obstructing good health governance in ways that foster obesity $(1,17-19)$. Many claims that free trade policies encourage the purchase of heavily packaged fried food while still preventing countries from behaving in their citizens' best interests $(1,20$, 21). On the other hand, Globalization could increase public health concerns by putting a premium on labour productivity. As a result of trade, foreign investment, and the proliferation of neoliberal (free market) policies, is Globalization to blame for the rise of obesity worldwide? We investigate this topic using the most recent research on childhood and adolescent obesity (ages 2-19) (22).

Due to the extreme significance of the trade of goods that promote obesity, Globalization's constraining impact on governments to protect civilization by public intervention, and the indirect effects of culture and behavioural changes that drive obesity, the global obesity crisis appears particularly important as a Globalization problem $(19,23)$. According to the World Health Organization, there are currently over 200 million overweight men and 300 million overweight women globally. Obesity is responsible for almost 2.8 million deaths per year, and 35.8 million Disability Adjusted Life Years (DALYs) per day are missed due to obesity-related disease (24). Obesity has become a sustainability problem because most obese people now live in developed countries $(25,26)$. Obesity associated diseases are especially devastating and expensive to manage, such as diabetes and heart disease, putting extreme pressure on already overstretched health budgets (27).

Obesity and overweightness have a substantial impact on production in terms of DALYs wasted. Indeed, diabetes and heart disease are the leading causes of death in most developing countries, and non- 
communicable diseases are expected to replace communicable diseases as the leading cause of death by $2020(1,2)$. Globalization, according to some researchers, has a strong connection to obesity.

Free markets promote the exchange of goods, especially food and other ingested commodities (28). People are eating more and more heavily refined foods all over the world. Traditional diets, which include more fruits and vegetables, are shifting toward higher-fat, higher-sugar meals, becoming more similar to Western, meat-based diets $(29,30)$. The exponential rise of fast-food chains, which sell trendy foods like pizza and hamburgers, has been blamed on Globalization for encouraging lower-quality foods $(20,31)$. People worldwide are allegedly shifting away from consuming fresh foods in favour of commodity foods, which are less expensive, more convenient, and have longer shelf lives (28).

Those around contend that Globalization has indirect impacts on obesity. One of the more compelling arguments is that Globalization and free-market economic conditions increase inequalities, contributing to the introduction and dissemination of unsustainable diets and lifestyles $(1,18,31,32)$. According to Kawachi and Kennedy (2002:17), the consequences of global injustice lead poor people to desire unsuitable consuming practices already adopted by the wealthy. As they write, "Poor people and poor countries make inappropriate consumption decisions and reduce savings and investment because they are misled by seeing the consumption patterns of richer peoples and nations". These arguments also claim that high disparity causes people to become demoralized due to relative deprivation. Depressed people cope by engaging in unhealthy eating behaviours, such as binge eating, and these social consequences are blamed on increased lethargy and other bad habits, resulting in "obesogenic" conditions (32). They accuse capitalism's "winner-take-all" capitalist values of dumping all of Western society's "bads" on emerging countries, which are ill-equipped socially and economically to deal with these "poor externalities" of unsuitable Western lifestyles and practices (33).

The economists initiated measuring Globalization based on some components was initiated by the economists to analyze the impact on economic growth (34). Globalization was measured based on imports, exports and foreign direct investment and confirmed it as a share in GDP, and all these were economic aspects. This means that Globalization is the only economic process, and the flow of capital and goods in the country is considered an impact. Recent measures for Globalization were based on the concept of three dimensions given by (35) (1) economic: market exchanges, the flow of capital, goods and services determine the perception of Globalization (2) political: incorporation of government policies on an international basis and (3) social: sharing of ideas, images and perceptions.

$(36,37)$ Explained additional dimensions have been developed called the KOF index of Globalization. Annual data was collected from the year 1970-2013 to measure Globalization on these aspects. In this paper, this new measure was assessed to analyze the impact of Globalization on low and middle-income countries with an increasing disorder that is obesity (38). Consumption of calories and decreased energy consumption as a whole is considered a vigilant factor of obesity and contributes to Globalization. Energy expenditure and consumption have been acting as stimulus between obesity impacting Globalization (e.g. $(39,40))$. The literature regarding this statement of the problem is quite limited. The 
nutritional transition has contributed to Globalization and its impact on obesity (Popkin B., 2001) (Popkin B. A., 2012).

Talking about technological change and Globalization combined with urbanization where food with great choice is offered, and increased use of cars and different mechanical aids resulting in reduced physical activity, and becoming more prone to obesity as high level of sugar intake and energy density factors in weight gain. (Te Morenga, 2013). Economic Globalization is manifested with foreign trade and investments displaying a great rise in agricultural business related foreign investments (Hawkes, 2006). These investments were invested in food production (Popkin B. A., 2012), and resulted nutritional transition as mentioned above in this literature making an economy more prone to gaining weight (Popkin B., 2006). Openness to trade leads to greater economic integration pursuing higher food market trades and nutritional transition associated with gaining weight (37). Such manifestation of economic Globalization with political factors is difficult to predict when measuring Globalization persuading the disorder of gaining weight. But the fact can be emphasized that political factors are influenced by economic trends (37). In addition to exploring the relative relevance of these various aspects of Globalization, another unique characteristic of our research is the incorporation of multiple Globalization indices into a national dataset providing individual-level data for up to 887,000 people. This helps to (a) use details on each individual's (objectively measured) overweight status and (b) account for specific individual-level covariates, e.g., schooling, age, residence, and household size e a function that can improve analytical accuracy over only looking at country-level statistics (Vogli, 2014). It's essential to manage for a spread of country-level factors that will simultaneously affect individual overweight risk. Country-level indicators of Globalization include GDP, Human Development Index. We aim to seek to seek out whether overall Globalization indeed increases the individual likelihood of overweight.

Public health organizations suggest that Globalization has been a great cause for obesity, hypothesizing the problem as "globesity". The results of this paper claimed that countries with high-level of income prioritise health. This results in effective labor productivity and human capital to sustain an economy's market even if the consumption might drive a rise. (Soysa, 2018). Globalization influences the economy of any country. Internationally, affordability and availability of processed foods and influx of food supply consisting of sweeteners and fat oils have undergone to the stage where diseases like obesity and diabetes have become a malfunction for an individual's health. These changes showed an absurd impact on the nutrition of the food supply resulting in obesity in countries. The prevalence of such an epidemic has led to deaths in most countries, creating an environment full of baneful diseases.

\section{Political Globalization}

Access to information through modern information and communication technology is another facet of Globalization. Since work has increasingly become independent of a static venue, ICT facilitates the transition of production locations from one country to another, having required criteria. The effect of such mobility could be a rise in low-income countries' income levels (41). 
In terms of politics and knowledge exchange, there are many facets of Globalization. First, there is a tendency to universalise ethnicity and representation in politics, public relations, education, labour markets, and usage, including formerly marginalised minorities. Marginson universality has traditionally been linked with state-driven modernization, industrialization, consumer economies, and progressive political activities. It means that various culturalism policies and diversity policies are implemented in social and public programs (42). Second, governmental complexity has risen, resulting in national assets being covered not so much by the number of fiscal disbursements and direct manufacturing in the public sector but rather by public institutes and the influence of individual behaviour. Third, as governments expand their economies, which have minimal deregulation of global economics and substantial constraints on national monetary policy, the foreign well-being facility has been harmed, and wage inequality and unemployment have risen. National governments can more easily bring measures to keep the world economy open and increase their competency by reducing the fit issues between national and foreign exchanges rather than taking decisions that mislead the domestic economic markets (42).

According to (38), economic freedom also decreases obesity, but social and political Globalization, especially political Globalization, increases obesity. As measured by the number of foreign embassies and participation in international organizations, political Globalization matters is the least intuitive and least theorized aspect of the topic.

\section{Methodology And Results}

The following study is based on a quantitative and deductive approach. The population is all the world countries, and the sample is 109 countries based upon the available data from 1990-2017 for 109 countries. Table 1 is highlighted to define global used variables in this article along with definition, data sources and variables type.

Table 1

- Variable Descriptions

\begin{tabular}{|llll|}
\hline $\begin{array}{l}\text { Variable } \\
\text { Names }\end{array}$ & Definition and Units & Data Source & $\begin{array}{l}\text { Variable } \\
\text { Type }\end{array}$ \\
\hline OBT & $\begin{array}{l}\text { Percentage of population who are } \\
\text { obese }\end{array}$ & $\begin{array}{l}\text { WHO/ } \\
\text { ourworldindata.org }\end{array}$ & Quantitative \\
\hline POPR & Rural population percentage of total & WDI $)$ & Quantitative \\
\hline POGLOB & Political Globalization Index & KOF Globalization Index & Quantitative \\
\hline TER & Gross enrolment in tertiary education & WDI & Quantitative \\
\hline
\end{tabular}

\subsection{Data Descriptive}

In Table 2, none of the variables has a mean value less than its standard deviation, which shows that the variables are under dispersed. While based on the Jarque Bera (JB) normality test, none of the variables 
is statistically normal. But since the data is large enough, the central limit theorem deems the variables asymptotically normal (Lind et al., 2000).

Table 2

- Descriptive Statistics of Variables

\begin{tabular}{|lllll|}
\hline Desc. Stat. & LOBT & LPOPR & LPOGLOB & LTER \\
\hline Obs. & 2594 & 2594 & 2594 & 2594 \\
\hline Mean & 2.384 & 3.553 & 4.154 & 2.894 \\
\hline Std. Dev & 0.823 & 0.727 & 0.353 & 1.235 \\
\hline Skewness & -1.082 & -1.579 & -1.216 & -0.952 \\
\hline Kurtosis & 3.190 & 7.141 & 4.974 & 3.286 \\
\hline JB (Prob) & $509(0.00)$ & $2931(0.00)$ & $1060(0.00)$ & $400(0.00)$ \\
\hline
\end{tabular}

Figure 1 provides the visualized correlation matrix between the selected variables. Her ewe can see that tertiary education (ter1) is strongly and directly associated with obesity (obt), while rural population (popr) is strongly inversely associated with obesity.

Figure 2 provides the line plots with the annual average of obesity and political Globalization, and here we can see a positive association between these two.

\subsection{Unit root tests and Cointegration}

The null hypothesis of a unit root test is that the series is non-stationary (having unit root), while the alternative hypothesis is that the series is stationary (having no unit root). The below table provides the LLC (Levin et al., 2002) unit root test.

Here in Table 3, we can see that other than LPOPR, all variables are stationary at level, while LPOPR is stationary at first difference. This indicates that these variables must be cointegrated to have nonspurious relationships.

Table 3

- Unit root test

\begin{tabular}{|lllll|}
\hline Variables & \multicolumn{2}{c}{ LLC test at level } & \multicolumn{2}{c|}{ LLC test at first difference } \\
\cline { 2 - 5 } & Statistic & Prob. & Statistic & Prob. \\
\hline LOBT & -85.96 & 0.000 & -72.80 & 0.000 \\
\hline LPGLOB & -6.52 & 0.000 & -22.31 & 0.000 \\
\hline LPOPR & 2.88 & 0.990 & -2.29 & 0.011 \\
\hline LTER & -38.07 & 0.000 & -148.37 & 0.000 \\
\hline
\end{tabular}


Table 4 provides the estimates of the KAO panel cointegration test. It can be seen from the probability values that the selected variables form a cointegrated relationship rather than a spurious relationship for the overall sample and all subsamples.

Table 4

- KAO cointegration test

\begin{tabular}{|lll|}
\hline & Kao T Statistic & Prob. \\
\hline Overall Data & -2.14 & 0.02 \\
\hline Low Human Development Sample & -1.41 & 0.08 \\
\hline Medium Human Development Sample & 2.64 & 0.00 \\
\hline High Human Development Sample & 2.08 & 0.02 \\
\hline Very High Human Development Sample & 5.44 & 0.00 \\
\hline
\end{tabular}

Table 5 provides the estimates of the Feasible Generalized Least Square model. Here we can see that for all models, the $\mathrm{R}$ squared values are healthy with a minimum of $87 \%$ variables explaining the variations in the obesity value at the national level. Here we can see that the increase in rural population proportion tends to reduce the average national obesity value because of the simplicity of food choices and the intensity of physical labour they endure in their agricultural chores. While assessing the effect of tertiary education, it is evident in all sub-models that an increase in tertiary enrollment decreases obesity. Still, the overall model increases the average obesity level for overall and all subsamples. This can be reasoned to several factors like the current education system not providing proper awareness related to the food choices individuals face. The second reason can be that increased enrollment increases their income, increasing consumption leading to obesity. 
Table 5

- FMOLS Model Estimates

\begin{tabular}{|llllll|}
\hline & Overall & $\begin{array}{l}\text { Low Human } \\
\text { Dev. }\end{array}$ & $\begin{array}{l}\text { Medium Human } \\
\text { Dev. }\end{array}$ & $\begin{array}{l}\text { High Human } \\
\text { Dev. }\end{array}$ & $\begin{array}{l}\text { Very High Human } \\
\text { Dev. }\end{array}$ \\
\hline LPGLOB & $\begin{array}{l}1.47 \\
(0.00)\end{array}$ & $5.25(0.00)$ & $-0.11(0.13)$ & $0.44(0.00)$ & $0.49(0.00)$ \\
\hline LPGLOB ${ }^{2}$ & $\begin{array}{l}-0.14 \\
(0.00)\end{array}$ & $-0.56(0.00)$ & $0.05(0.00)$ & $-0.08(0.00)$ & $-0.17(0.00)$ \\
\hline $\begin{array}{l}\text { LPGLOB* } \\
\text { LTER }\end{array}$ & $\begin{array}{l}-0.06 \\
(0.00)\end{array}$ & $0.31(0.00)$ & $0.14(0.00)$ & $0.15(0.00)$ & $0.27(0.00)$ \\
\hline LTER & $\begin{array}{l}0.60 \\
(0.00)\end{array}$ & $-1.08(0.00)$ & $-0.22(0.00)$ & $-0.45(0.00)$ & $-0.83(0.00)$ \\
\hline LPOPR & -0.38 & $-0.10(0.02)$ & $-1.11(0.00)$ & $-1.20(0.00)$ & $-0.20(0.00)$ \\
\hline Sample & $(0.00)$ & & & & \\
\hline R squared & 0.94 & 0.94 & 0.98 & 0.97 & 0.87 \\
\hline
\end{tabular}

While assessing the dynamics of political Globalization, other than medium human developed countries, the coefficient of political Globalization is positive. In contrast, the coefficient of squared of political Globalization is negative, which means that political Globalization follows an inverted U-shaped relationship. Whereby low level of Globalization is causing obesity while high levels of Globalization are causing fall in obesity. For the case of medium human development countries, the political Globalization coefficient is insignificant. In contrast, the squared political Globalization coefficient is positive, showing a linear positive effect of political Globalization on obesity. While studying the interacting effect of tertiary enrollment, it can be seen that the increase in enrollment in the overall sample reduces the globesity effect. In contrast, for the case of sub samples, it increases the globesity effect. Below figure 3 to 7 provides the situation of moderating effect of tertiary enrollment on globesity.

\section{Discussion And Conclusions}

This study explored the perspective of the political Globalization of the country and its role in noncommunicable diseases like obesity. Countries that tend to become more globalized, especially in the political sense, start to gather more international resources by lobbying with their allies. This study has developed a model of estimating the national level of obesity as a percentage of the total population by using indicators like the rural population as percentage of total, political Globalization index and tertiary enrollment $(38,43)$.

This study further hypothesises that the effect of political Globalization on obesity is non-linear. Instead, it is quadratic. Within this hypothesis, a low level of political Globalization tends to increase obesity because countries cannot sway international decisions and resources towards them. While the high level of political Globalization tends to reduce obesity because they can control and amends the international 
decisions(44). Lastly, tertiary enrollment is used as a moderator to the quadratic specification of political Globalization (45).

This study has selected the data of 109 countries across 1990-2017. For the case of correlations, the rural population has the highest indirect association with obesity, while tertiary enrollment has a weak positive association. Over time, it is to be seen that both obesity and political Globalization has increased in the sample countries (46). For the case of data analysis, this study has used panel unit root and panel cointegration tests for the model. This study has developed five samples, one overall and one each for each human development group. The results showed that the variables are non-stationary; hence conventional panel data models will not suffice (38). This study has resorted to dynamic panel data models, which require the significance of panel cointegration tests, which were confirmed in Table 4.

Using the Fully Modified OLS model (in Table 5), the results show that for all models rural population had an adverse effect on obesity and was categorised by their simplicity in living and higher human activity engagement. Tertiary enrollment tends to show the negative effect for few models while also having a positive effect on others. The political Globalization level variable was positive for all models except medium human development, while the political Globalization squared was negative except medium human development. This shows that political Globalization had an inverted U-shaped effect for all cases while a medium human development case had a U-shaped effect. In the overall sample, tertiary enrollment was negatively moderating the obesity increasing effect of political Globalization while it is increasing the effect in all other cases.

\section{Policy Implications}

This study is instrumental in devising an international strategy in modifying and transforming the health patterns of the nation. Higher obesity will affect the nation's productivity; thus, policymakers need to motivate and provide the means to reduce obesity. This model showed that policymakers should provide the facilities at the rural level so that the people do not migrate towards cities, higher rural population will help mitigate obesity. Promoting higher education will help in spreading awareness among the masses. This will help in reducing obesity. For the case of tertiary enrollment (except for the medium human development), this study suggests the policymakers increase the Globalization beyond the turning point of political Globalization. This way increase in Globalization will help in managing obesity.

\section{Abbreviations}

DALYs: Disability Adjusted Life Years

WDI: World Development Indicators by World Bank

WHO: World Health Organization

GDP: Gross Domestic Product

Page $11 / 20$ 
Globesity: Global Obesity

KOF: Name of Globalization Index

OBT: Obesity

POPR: Rural Population

POGLOB (Pol. Glob.): Political Globalization

TER: Tertiary Enrollment

JB: Jarque Bera Test

Desc. Stat.: Descriptive Statistics

KAO panel cointegration test

Prob.: Probability

LLC: Levin, Lin, and Chu (2002, LLC) Lagrange multiplier panel unit root test

LOBT: Log of Obesity

LPGGLOB: Log of Political Globalization

LPOPR: Log of Rural Population

LTER: Log of Tertiary Education

FGLS: Feasible Generalized Least Square model

OLS: Ordinary Least Square Regression Model

\section{Declarations}

Authors' contributions: MM and ZTAZ conceived the idea and worked on the research methodology. RA and SS helped in supervising the article. MM and NA worked on the results and analysis, and interpretation of model results. ZTAZ supervised the project and intensively edited the language of the manuscript. MM approved and read the final manuscript and participated in the critical appraisal of the manuscript. All authors have read and agreed to the published version of the manuscript.

Acknowledgements: I would like to thank respected professors and affiliated institutes.

Ethics approval and consent to participate: Not applicable 
Availability of data and materials: The datasets generated and/or analysed during the current study are available in the [KOF, WDI \& WHO] repositories, [https://kof.ethz.ch/en/forecasts-andindicators/indicators/kof-globalisation-index.html, https://databank.worldbank.org/source /worlddevelopment-indicators and https://www.who.int/data/gho/publications/world-health-statistics]

\section{Consent for publication: Yes}

Competing interests: The authors declare that they have no competing interests

Funding: Not applicable

\section{References}

1. de Soysa I, de Soysa AK. Do Globalization and Free Markets Drive Obesity among Children and Youth? An Empirical Analysis, 1990-2013. Int Interact. 2018;44(1):88-106.

2. Zahra A, Lee EW, Sun LY, Park JH. Cardiovascular disease and diabetes mortality, and their relation to socio-economical, environmental, and health behavioural factors in worldwide view. Public Health. 2015;

3. James WPT. Obesity: A global public health challenge. Clin Chem. 2018;64(1):24-9.

4. Malik VS, Willett WC, Hu FB. Global obesity: Trends, risk factors and policy implications. Nature Reviews Endocrinology. 2013.

5. Misra A, Khurana L. Obesity and the metabolic syndrome in developing countries. J Clin Endocrinol Metab. 2008;93(11 SUPPL. 1):9-30.

6. Finucane MM, Stevens GA, Cowan MJ, Danaei G, Lin JK, Paciorek CJ, et al. National, regional, and global trends in body-mass index since 1980: Systematic analysis of health examination surveys and epidemiological studies with 960 country-years and 9.1 million participants. Lancet. 2011;

7. Raine KD. Obesity in canada. Can J Diabetes [Internet]. 2004;152. Available from: https://secure.cihi.ca/estore/productSeries.htm?pc=PCC239

8. Popkin BM, Gordon-Larsen P. The nutrition transition: Worldwide obesity dynamics and their determinants. Int J Obes. 2004;28:S2-9.

9. Swinburn BA, Sacks G, Hall KD, McPherson K, Finegood DT, Moodie ML, et al. The global obesity pandemic: Shaped by global drivers and local environments. The Lancet. 2011.

10. Raine KD. Obesity epidemics: Inevitable outcome of globalization or preventable public health challenge? Int J Public Health. 2012;57(1):35-6.

11. Basch CH, Samuel L, Ethan D. Obesity, diabetes and heart disease: Effects of globalization on population health, preventive efforts, and the importance of social change. Int J Heal Promot Educ. 2013;51(4):185-97.

12. Li Q, Reuveny R. Economic Globalization and Democracy: An Empirical Analysis. Br J Polit Sci. 2017;33(1):29-54. 
13. Brady D, Beckfield J, Seeleib-Kaiser M. Economic globalization and the welfare state in affluent democracies, 1975-2001. Am Sociol Rev. 2005;70(6):921-48.

14. McCann P. Globalization and economic geography: the world is curved, not flat. Cambridge $J$ Reg Econ Soc [Internet]. 2008;1(3):351-70. Available from: https://doi.org/10.1093/cjres/rsn002

15. Lambin EF, Meyfroidt P. Global land use change, economic globalization, and the looming land scarcity. Proc Natl Acad Sci U S A. 2011;108(9):3465-72.

16. Monda KL, Gordon-Larsen P, Stevens J, Popkin BM. China's transition: The effect of rapid urbanization on adult occupational physical activity. Soc Sci Med. 2007;64(4):858-70.

17. Delpeuch F, Maire B, Monnier E, Holdsworth M. Globesity: A planet out of control? Globesity: A Planet Out of Control? 2013.

18. Kawachi I, Kennedy B. The health of nations: why inequality is harmful to your health? J Epidemiol Community Heal. 2003;

19. Schrecker T, Bambra C. How politics makes us sick: Neoliberal epidemics. How Politics Makes Us Sick: Neoliberal Epidemics. 2015.

20. Blouin C, Chopra M, van der Hoeven R. Trade and social determinants of health. The Lancet. 2009.

21. Labonte R, Sanger M. Glossary on the World Trade Organisation and public health: Part 2. Journal of Epidemiology and Community Health. 2006.

22. Fryar CD, Carroll MD, Ogden CL. Prevalence of Overweight, Obesity, and Severe Obesity Among Children and Adolescents Aged 2-19 Years: United States, 1963-1965 Through 2015-2016. Natl Cent Heal Stat Heal E-Stats. 2018;(September):1-6.

23. Popkin BM. Global nutrition dynamics: The world is shifting rapidly toward a diet linked with noncommunicable diseases. American Journal of Clinical Nutrition. 2006.

24. The GBD 2015 Obesity Collaborators. Health Effects of Overweight and Obesity in 195 Countries over 25 Years. N Engl J Med. 2017;377(1):13-27.

25. Ng M, Fleming T, Robinson M, Thomson B, Graetz N, Margono C, et al. Global, regional, and national prevalence of overweight and obesity in children and adults during 1980-2013: A systematic analysis for the Global Burden of Disease Study 2013. Lancet. 2014;

26. Poobalan A, Aucott L. Obesity Among Young Adults in Developing Countries: A Systematic Overview. Current obesity reports. 2016.

27. Bloom DE. The Shape of Global Health. Finance Dev. 2014;

28. Thow AM, Hawkes $C$. The implications of trade liberalization for diet and health: A case study from Central America. Global Health. 2009;

29. Barry Popkin and Mendez Michelle. The Rapid Shifts in Stages of the Nutrition Transition: The Global Obesity Epidemic. In Globalization and Health, edited by Ichiro Kawachi, and Sarah Wamala. Oxford: Oxford University Press; 2007. 68-80 p.

30. Hawkes Corinna, Chantal Blouin, Spencer Henson, Nick Drager and LD. Trade, Food, Diet and Health: Perspectives and Policy Options. Oxford: Blackwell; 2010. 
31. Offer A, Pechey R, Ulijaszek S. Obesity under affluence varies by welfare regimes: The effect of fast food, insecurity, and inequality. Econ Hum Biol. 2010;

32. Tuters S. Wilkinson, R., \& Pickett, K. (2009). The Spirit Level: Why More Equal Societies Almost Always Do Better. London: Allen Lane.. Leadersh Policy Sch. 2012;

33. Coburn D. Income inequality, social cohesion and the health status of populations: The role of neoliberalism. Social Science and Medicine. 2000.

34. Dollar D, Kraay A. Trade, growth, and poverty. Econ J. 2004;

35. Keohane RO, Nye JS. Globalization: What's new? what's not? (and so what?). Foreign Policy. 2000;

36. Dreher A, Sturm JE, Ursprung HW. The impact of globalization on the composition of government expenditures: Evidence from panel data. Public Choice. 2008;134(3-4):263-92.

37. Dreher A. Does globalization affect growth? Evidence from a new index of globalization. Appl Econ. 2006;38(10):1091-110.

38. Goryakin Y, Lobstein T, James WPT, Suhrcke M. The impact of economic, political and social globalization on overweight and obesity in the 56 low and middle income countries. Soc Sci Med [Internet]. 2015;133:67-76. Available from: http://dx.doi.org/10.1016/j.socscimed.2015.03.030

39. Hlaing WW, Nath SD, Huffman FG. Assessing overweight and cardiovascular risks among college students. Am J Heal Educ [Internet]. 2007;38(2):83-90. Available from: https://doi.org/10.1080/19325037.2007.10598948

40. Finkelstein EA, Ruhm CJ, Kosa KM. Economic causes and consequences of obesity. Annu Rev Public Health. 2005;26:239-57.

41. Aronowitz S. The jobless future: Sci-tech and the dogma of work. U of Minnesota Press; 1994.

42. Marginson S. After globalization: Emerging politics of education. J Educ Policy. 1999;14(1):19-31.

43. Schrecker T. Globalization and health: political grand challenges. Rev Int Polit Econ. 2020;27(1).

44. de Soysa I, de Soysa AK. Do Globalization and Free Markets Drive Obesity among Children and Youth? An Empirical Analysis, 1990-2013. Int Interact. 2018;

45. Destek MA. Investigation on the role of economic, social, and political globalization on environment: evidence from CEECs. Environ Sci Pollut Res. 2020;27(27).

46. Cornia GA. Globalization and health: Results and options. Vol. 79, Bulletin of the World Health Organization. 2001.

\section{Figures}




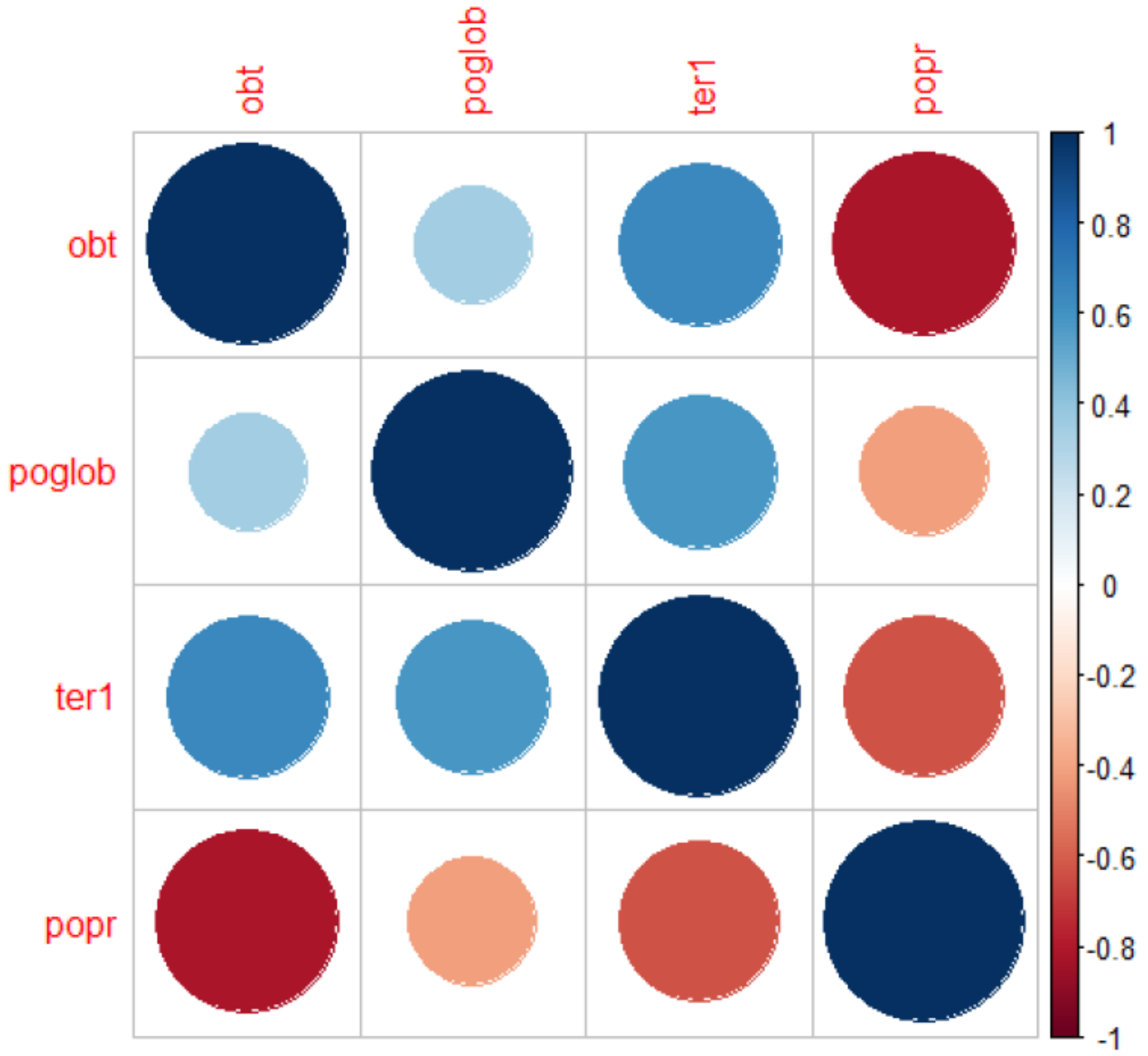

Figure 1

Correlation Plot 
Obesity and Political Globalization

Normalized Transformation

$$
\text { Legend text - Obesity - Pol. Glob. }
$$

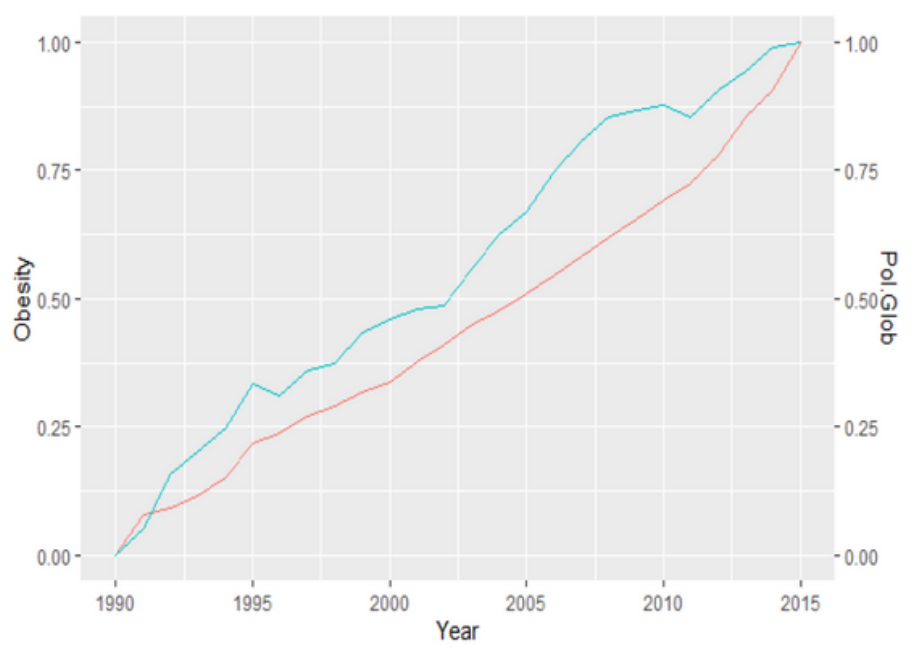

Figure 2

Growth of Political globalization and Obesity

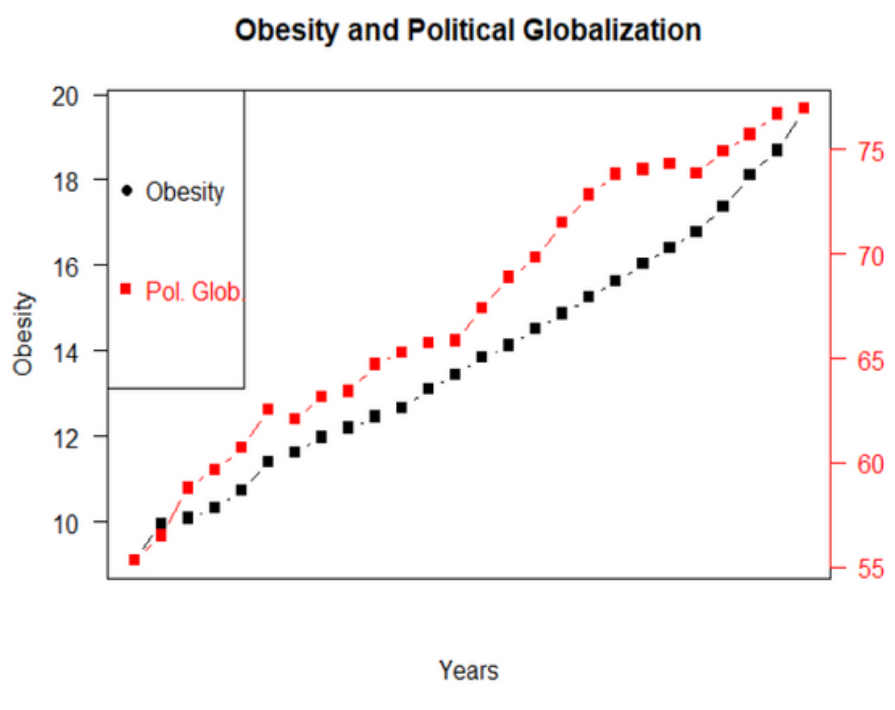

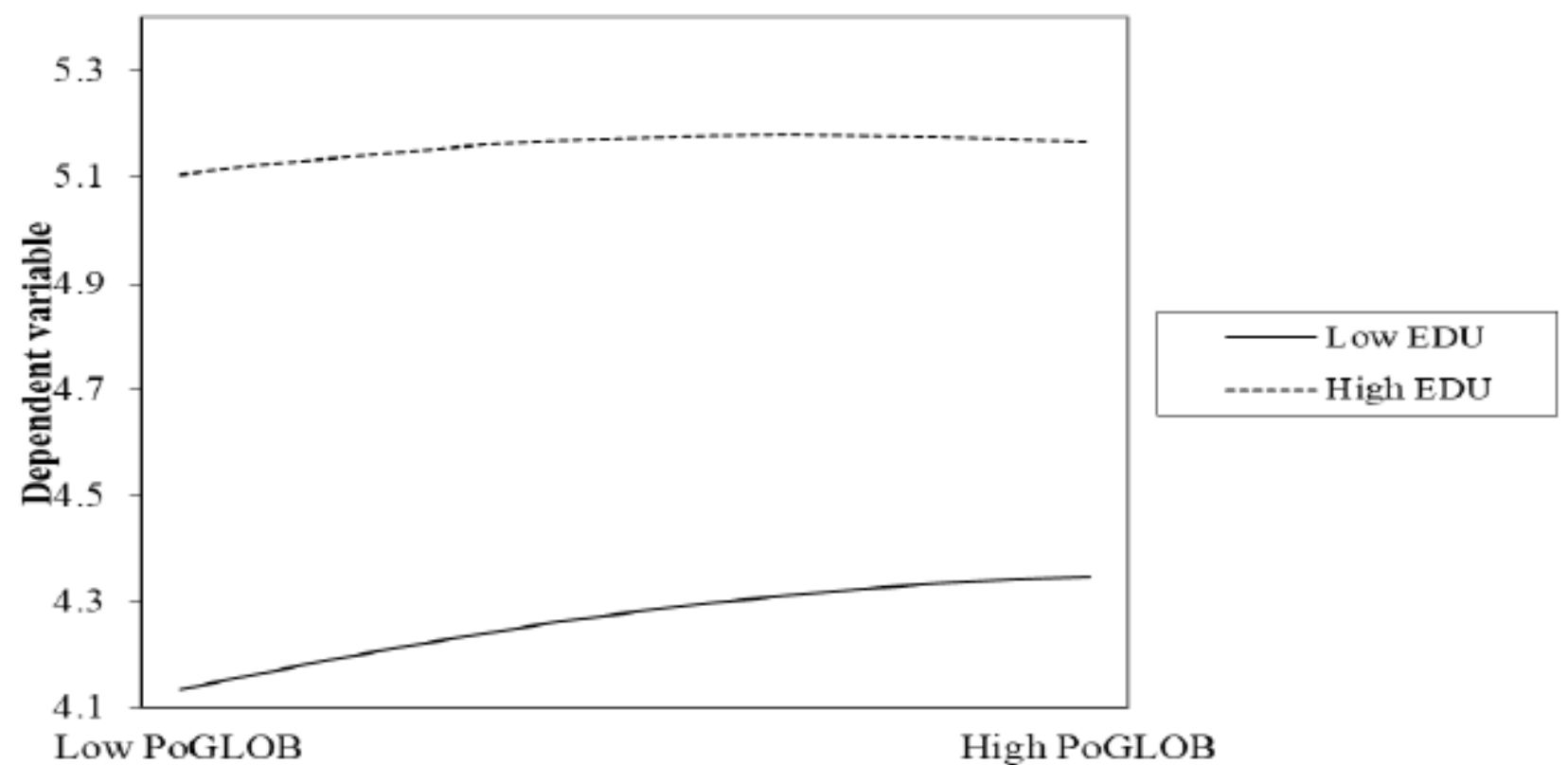

Figure 3

Overall Sample 


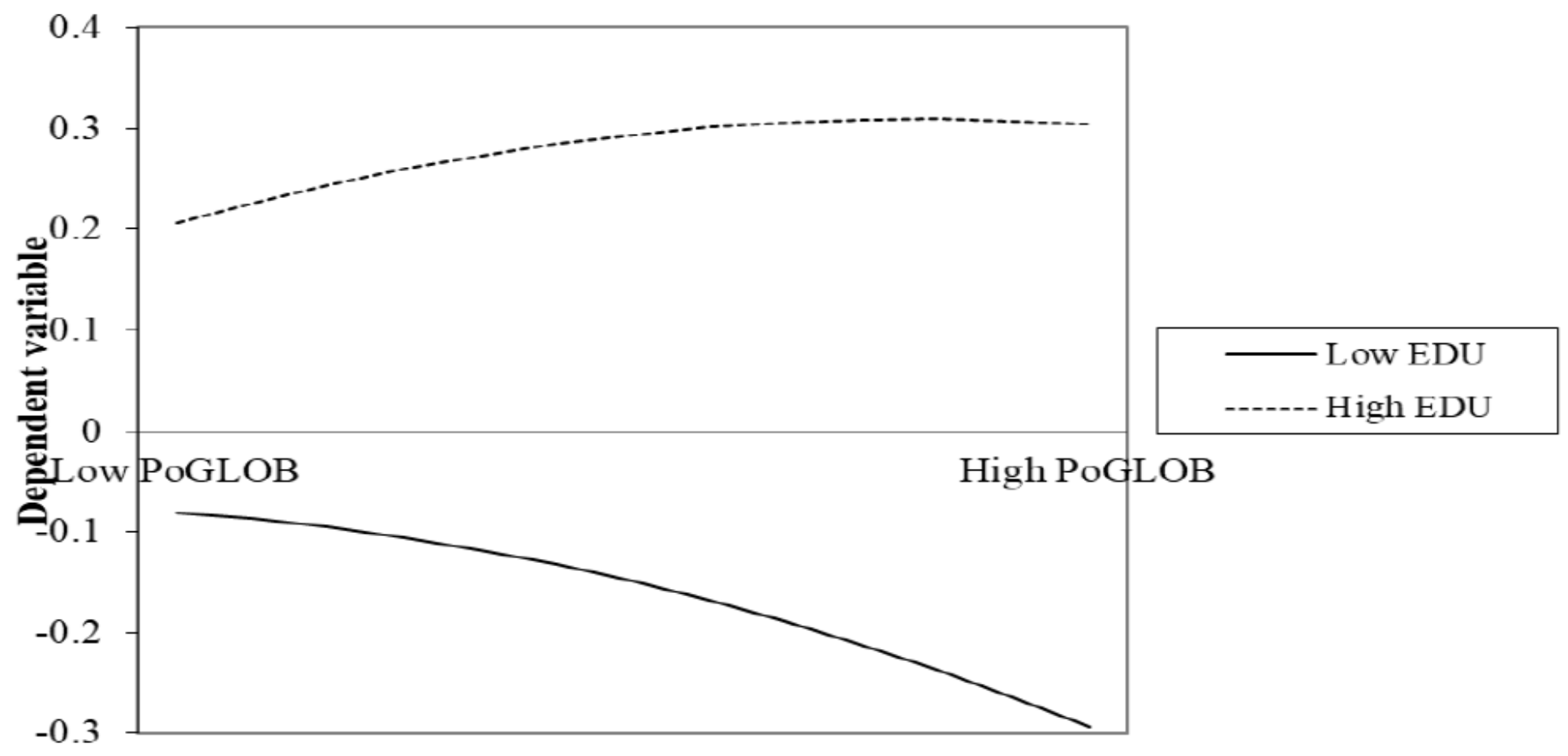

Figure 4

Very High Human Dev.

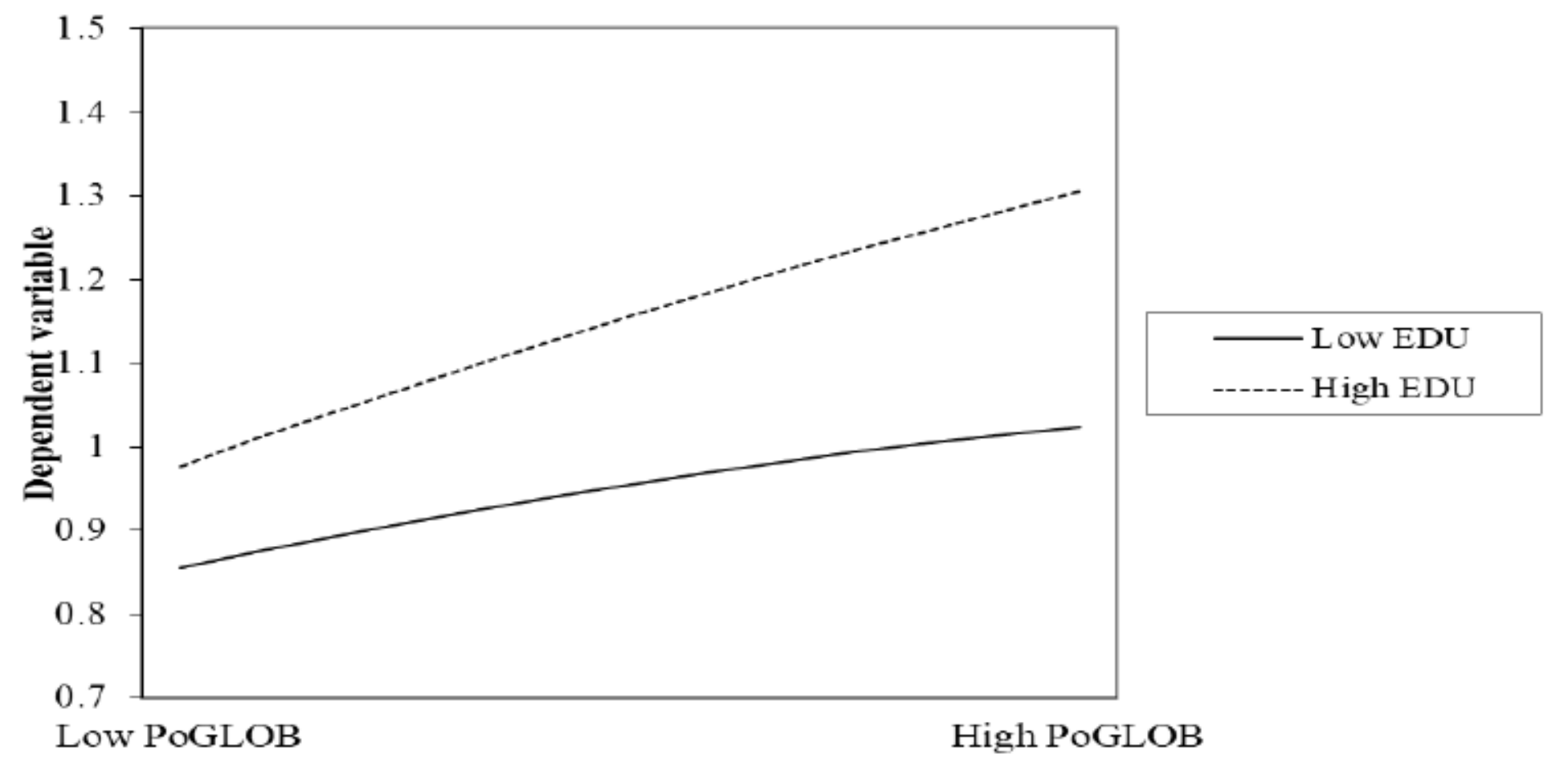

Figure 5

high human dev. 


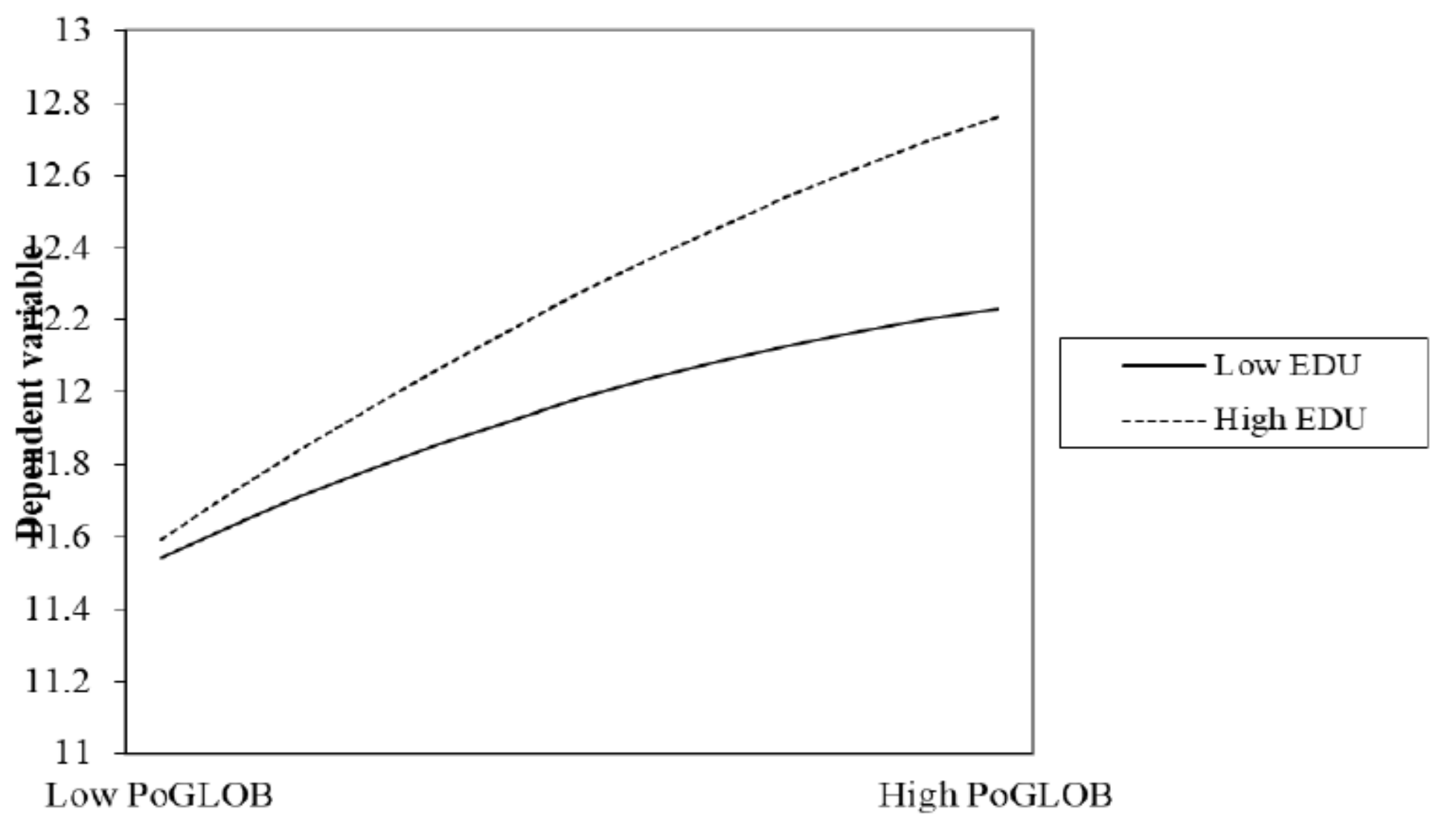

Figure 6

low human dev.

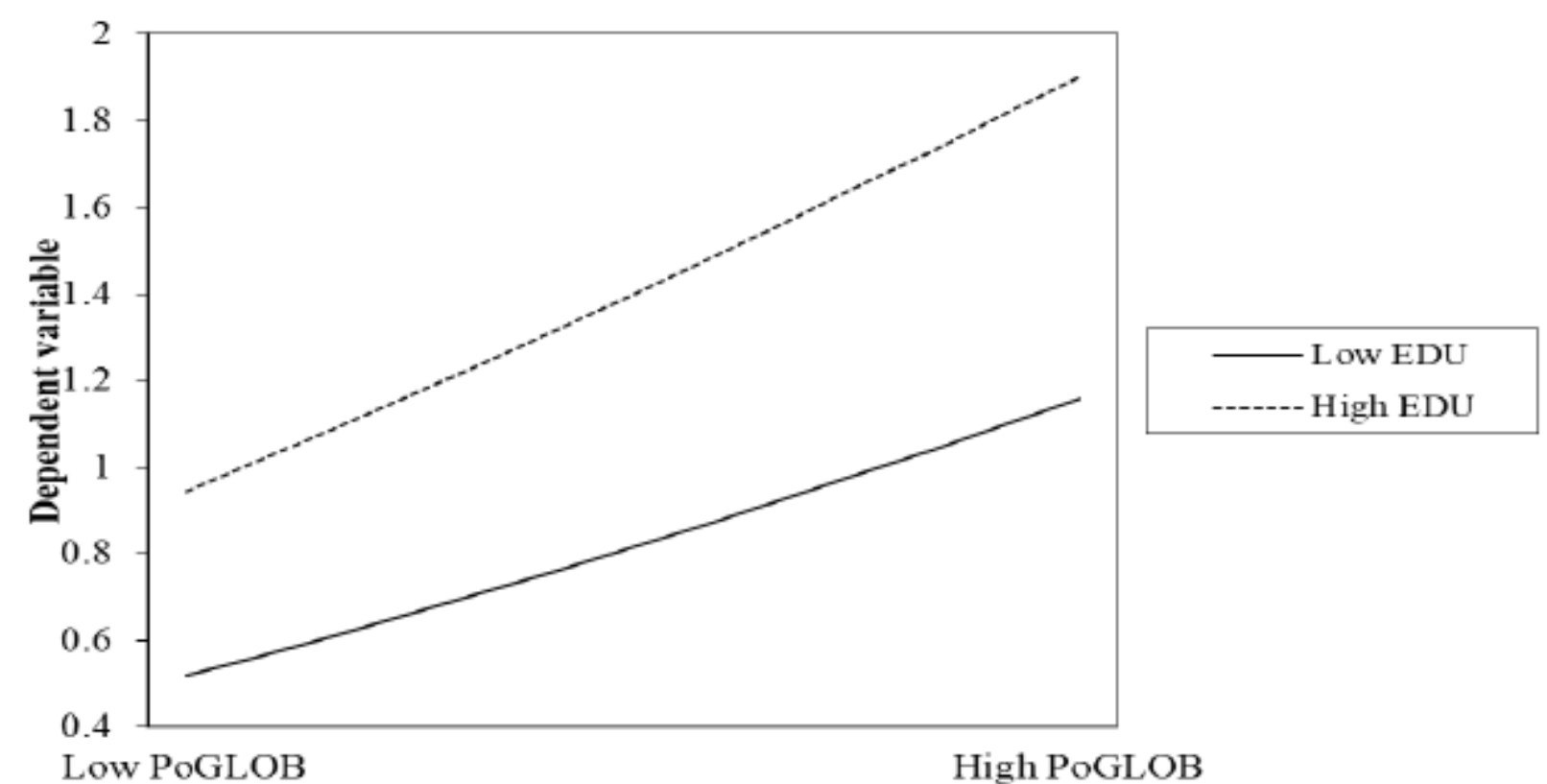

Page $19 / 20$ 
Figure 7

medium human dev. 